At the tanyard with which I am connected, we tan a large number yearly, including many cotton nets. Not only does it render them more durable, but in some cases, where wet nets have heated and become tender, their toughness has been restored by tanning. I cannot attempt to explain the chemical action which takes place, and, indeed, the still more important ones by which leather is produced are very imperfectly understood.

North Shields, Sept. 26

HENRY R. PROCTER

\section{The Intended Engineering College}

IN my letter on the above subject, I alluded to Mr. Mason's magnificent foundation of an educational institution in Birmingham, and by a queer inadvertence wrote the Christian name "Oliver"; and shall be much obliged if you will insert this correction of my mistake. It is Mr. Fosinh Mason, the wellknown pen manufacturer and founder of the orphanage and almshouses at Erdington, who is so liberally and judiciously enriching the Midland metropolis

\section{W. Mattieu Willians}

\section{The Haze Accompanying Auroral Displays}

I DouBT if the haze, seen before and during Aurora, has received sufficient attention. The beautiful displays which we in Canada have so frequently seen of late, have been well adapted to lead us to inquire into their cause ; and I think in making observations, the beauty of the luminous portion has led us to overlook other things which are equally important.

On the night of April 15, 1869, we had a grand exlibition of Aurora at Toronto. It spread itself all over the heavens, form: ing a glorious canopy, filling the south as well as the north.

Previous to any auroral display, however, the atmosphere became thick and hazy; I was viewing the setting moon through a telescope, and though there were no clouds, I found the definition become extremely bad; I thouglit my breath must have got on the eye-piece, but soon found this was not the case. I then went outside, and on looking round, found the whole atmosphere full of haze. It had not the appearance of fog, but the whole air seemed thick and turbid, and shortly auroral columns commenced forming. This haze was visible for hours. Referring to this feature, Prof. Kingston says (American Fournal of Science, July 1869, p. 65):-" "Throughout the night, a generally diffused luminosity prevailed, such as is commonly seen with a full moon and hazy sky. This was evidently not occasioned by the moon, which was scarcely four days old, and was low in the horizon, but was part of the aurora itself, the brilliancy of whose more active features it greatly impaired." This haze is seldom seen spread in this way all around us; but it is tisually seen as a bank in the north, and is surmounted by the auroral arch; stars can be seen through it, but it greatly dims their lustre. Prof. Loomis says :-- "The slaty appearance of the sky, which is a common feature of great auroral exhibitions, arises from the condensation of the vapour of the air, and this condensed vapour probably exists in the form of minute spicula of ice or flakes of snow. Fine flakes of snow have been repeatedly observed to fall during the exhibition of auroras, and this snow only slightly impairs the transparency of the atmosphere without presenting the appearance of clouds. It produces a turbid appearance of the atmosphere, and causes thit dark bank which in the United States rests on the northerm horizon. This turbidness is more noticeable near the horizon than it is at great elevations, because near the horizon the line of vision traverses a greater extent of this hazy atmosphere. When the aurara covers the whole heavens, the entire atmosphere is filled with this haze, and a dark segment may be observed resting on the southern horizon."

Whilst approving of the professor's description, I must dissent from his explanation of the cause. This haziness is seen during our hot summer nights, as well as our cold ones; and I have seen it when snow-flakes would be out of the question in such a temperature. Many reasons leads me to regard this haze as cosmical, falling on our earth from without ; but at present, I will call attention to the appearance only, reserving my explana. tion for a future time.

A. Elvins

\section{NOTES}

IT is with very great regret that we have to announce the death, at the age of fifty-two, of Dr. William Allen Miller, Professor of Chemistry in King's College, London, and treasurer and vice-president of the Royal Society. Professor Miller's writings have earned for him a position in the literature of chemistry, from which he will be very greatly missed.

WE understand that Professor Allman has resigned the Chair of Natural History in the University of Edinburgh. It has long been felt that the subjects of Geology and Mineralogy which have hitherto been taught from this Chair are of such vast and growing importance and extent, that they can no longer be properly included in it when a successor is appointed. It gives us the greatest pleasure to state that Sir Roderick Murchison, who has already done so much for the geology of his native country, has munificently come forward with the offer of $6,000 \%$. towards the endowment of a separate Chair of Geology and Mineralogy, on the understanding that on this, as on former occasions, the Government will supplement the private grant by an equal sum. Here then we have an admirable occasion for the Government to show itself alive to the importance of fostering the cultivation of those sciences on which especially the future welfare of the country must largely depend.

THE new Faculty of Science in University College, London, was opened on Tuesday last, by an inaugural address by Prof. A. W. Williamson, F.R.S. The discourse was devoted to an exposition of the importance of scientific method, and of the value of a scientific training, as an introduction even to the life of an ordinary man of business.

IN addition to his discourse to the Social Science Congress at Newcastle, Dr. Lyon Playfair delivered, on Thursday evening last, the inaugural address on opening the session of the Birmingham and Midland Institute. The subject of the lecture was announced as "The Inosculation of the Arts and Sciences;" and in its course the lecturer discussed the intimate union between science and labour. It is not science which creates labour or the industries flowing from it. On the contrary, science is the progeny of the industrial arts on the one side, and on the other of the experiences and perceptions which gradually attach themselves to these arts, so that the evolution of science from the arts is the first circumstance of human progress, which, however, quickly receives development and impulse from the science thus evolved. Industrial labour, then, is one of the parents, and science the child ; but, as often happens in the world, the son becomes richer than the father, and raises his position. Apologising for the apparently pedantic form of the word, Dr. Playfair said lie proposed to treat of the "inosculation" of arts and sciences, their junction with open moutlss, as when two arteries join and mingle their contents. It will be seen that science does not depend upon facts alone, but upon the increase of mental conceptions which can be brought to bear upon them; these conceptions increase as slowly as the common knowledge. derived from experience-they both descend by inheritance from one generation to another, until science in its progress becomes a prevision of new knowledge by light reflected from the accumulated common knowledge of the past. In the progress of time common knowledge passes into scientific knowledge. The amazing changes which have taken place since 1838 are due to our better conceptions of forces and their -mutual relations and conversions. Formerly heat, light, electricity, mag: netism, and chemical affinities, were thought to be separate and independent existences, not even related to eacl other. Now we know that forces are convertible and interchangeable. This knowledge has already given great stimulus to their application, and will do so more in the future. Further, we know that 